\title{
Better Hemodynamics and Less Antihypertensive Medication: Comparison of Scalp Block and Local Infiltration Anesthesia for Skull-Pin Placement in Awake Deep Brain Stimulation Surgery
}

\author{
Krauss, Philipp ; Marahori, Natalia Athanasia ; Oertel, Markus Florian ; Barth, Florian ; Stieglitz, \\ Lennart Henning
}

\begin{abstract}
OBJECTIVE In deep brain stimulation (DBS) surgery, acute high blood pressure (BP) is a risk factor for intracranial hemorrhage. To minimize pain and hypertensive conditions, sufficient local anesthesia is mandatory. We evaluated whether local instillation of anesthetics (LA) or a scalp block (SB) is superior concerning intraoperative hemodynamics and analgesia. METHODS We retrospectively analyzed intraoperative cardiovascular parameters and perioperative medication in 47 patients $(\mathrm{LA}=29$, $\mathrm{SB}=18$ ) undergoing DBS surgery. Primary study end points were intraoperative systolic BP and heart rate. Secondary end points were use of intraoperative antihypertensives and perioperative analgesics. RESULTS Patients who had SB showed lower mean systolic BP and heart rate compared with patients who had LA. Patients who had LA required more antihypertensive medication to stabilize BP. BP was higher, particularly during the first 90 minutes of surgery, in patients who had LA. Thereafter, more antihypertensives were necessary to achieve sufficient BP control in the LA group. The dose of analgesics did not differ significantly between both groups during and after surgery. CONCLUSIONS Our data suggest that SB might be superior to LA for DBS surgery with respect to BP control and hemodynamics. The need for analgesics does not differ substantially between both anesthetic treatment options.
\end{abstract}

DOI: https://doi.org/10.1016/j.wneu.2018.08.210

Posted at the Zurich Open Repository and Archive, University of Zurich ZORA URL: https://doi.org/10.5167/uzh-158325

Journal Article

Accepted Version

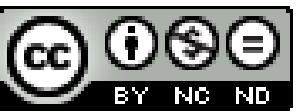

The following work is licensed under a Creative Commons: Attribution-NonCommercial-NoDerivatives 4.0 International (CC BY-NC-ND 4.0) License.

Originally published at:

Krauss, Philipp; Marahori, Natalia Athanasia; Oertel, Markus Florian; Barth, Florian; Stieglitz, Lennart Henning (2018). Better Hemodynamics and Less Antihypertensive Medication: Comparison of Scalp Block and Local Infiltration Anesthesia for Skull-Pin Placement in Awake Deep Brain Stimulation Surgery. World Neurosurgery, 120:e991-e999.

DOI: https://doi.org/10.1016/j.wneu.2018.08.210 
Neurosurgery

\section{Elsevier Editorial System(tm) for World}

Manuscript Draft

Manuscript Number:

Title: Better hemodynamics and less antihypertensive medication:

Comparison of scalp block and local infiltration anesthesia for skull-pin placement in deep brain stimulation surgery.

Article Type: Original Article

Keywords: awake neurosurgery; deep brain stimulation; risk reduction; scalp block; stereotactic surgery

Corresponding Author: Mr. Philipp Krauss, M.D.

Corresponding Author's Institution: UniversitätsSpital Zürich

First Author: Philipp Krauss, M.D.

Order of Authors: Philipp Krauss, M.D.; Natalia A Marahori, M.D.; Florian Barth, M.D.; Markus F Oertel, M.D.; Lennart H Stieglitz, M.D.

Abstract: Objective: In deep brain stimulation (DBS) surgery, acute high blood pressure (BP) is a risk factor for intracranial hemorrhage (ICH).

To minimize pain and hypertensive conditions, sufficient local anesthesia

is mandatory. We evaluated whether local instillation of anesthetics (LA)

or a scalp block (SB) is superior concerning intraoperative hemodynamics

and analgesia.

Methods: We retrospectively analyzed intraoperative cardiovascular

parameters and perioperative medication of 47 patients ( LA $=29, \mathrm{SB}=18$ )

undergoing DBS surgery. Primary study endpoints were intraoperative systolic BP and heart rate (HR). Secondary endpoints were use of intraoperative antihypertensives and perioperative analgesics.

Results: SB patients showed lower mean systolic BP and HR compared to LA patients. LA patients required more antihypertensive medication to stabilize BP. BP was higher particularly during the first 90 minutes of surgery in LA patients. Thereafter, more antihypertensives were necessary to achieve sufficient BP control in the LA group. The dose of analgesics did not differ significantly between both groups during and after surgery.

Conclusion: Our data suggest that SB might be superior to LA for DBS surgery with respect to BP control and hemodynamics. The need for analgesics differ not substantially between both anesthetic treatment options. 
Title:

4 Better hemodynamics and less antihypertensive medication: Comparison of scalp block and local

5 infiltration anesthesia for skull-pin placement in deep brain stimulation surgery.

6 Short title:

7 SB or LA for risk reduction in awake DBS?

8

9 AUTHOR NAMES AND AFFILIATIONS:

10 Philipp KRAUSS, MD#*(P.K.), Natalia Athanasia MARAHORI, MD ${ }^{1}$ (N.A.M.), Florian

11 BARTH, MD ${ }^{2}$ (F.B.), Markus Florian OERTEL, MD ${ }^{1}$ (M.F.O.), Lennart Henning STIEGLITZ, $12 \mathrm{MD}^{1}$ (L.H.S.)

13

$14{ }^{1}$ Department of Neurosurgery, University Hospital of Zurich, Zurich, Switzerland

$15{ }^{2}$ Institute of Anesthesiology, University Hospital of Zurich, Zurich, Switzerland 16

17 \# Corresponding author: Department of Neurosurgery, University Hospital of Zurich,

18 Frauenklinikstrasse 10, 8091 Zurich, Switzerland; ph.krauss@ gmx.de; Phone: 0041/44/2552660;

19 Fax: 0041/44/255 4505

$20 *$ These authors contributed equally to this work

21

22 Abstract word count: 193

23 Manuscript word count: 2463

24 Reference count: 40

25 Table count: 2

26 Figure count: 6

27 Supplementary material: 1 Figure, 1 Table 
2 Key words:

3 awake neurosurgery, deep brain stimulation, risk reduction, scalp block, stereotactic surgery

4

5 DECLARATION OF AUTHORSHIP and CONTRIBUTION:

6 All authors confirm that the manuscript and the order of listed authors has been read and

7 approved by all named authors. L.H.S., M.F.O., F.B. and P.K. devised, initiated and supervised

8 the study. L.H.S., M.F.O, F.B., N.A.M. and P.K. collected all data. P.K. and N.A.M. analyzed

9 and designed corresponding figures and tables. L.H.S., M.F.O. and P.K. performed the surgeries.

10 P.K. and N.A.M. wrote the manuscript with input from all authors. 


\section{Conflict of interest declaration:}

All authors declare that the article content was composed in the absence of any commercial or financial relationships that could mean a potential conflict of interest. This research did not receive any specific grant from funding agencies in the public, commercial, or not-for-profit sectors 
Abbreviations: $\mathrm{BP}=$ blood pressure, $\mathrm{CT}=$ computed tomography, $\mathrm{DBS}=$ deep brain stimulation, DPS = definite stimulation point, $\mathrm{ET}=$ essential tremor, $\mathrm{GA}=$ general anesthesia, $\mathrm{HR}$ = heart rate, $\mathrm{ICH}=$ intracranial hemorrhage, $\mathrm{IPG}=$ impulse generator, i.v. = intravenous, $\mathrm{LA}=$ local anesthesia, $\mathrm{OR}=$ operation room, $\mathrm{PD}=$ Parkinson's disease, $\mathrm{SD}$ = standard deviation, $\mathrm{SB}=$ scalp block, $\mathrm{SEM}=$ standard error of the mean 


\section{HIGHLIGHTS:}

- Optimal cardiovascular parameters are known to reduce surgery related risks in DBS.

- Scalp block is superior to local anesthesia in providing optimal hemodynamics.

- Scalp block patients need significantly less antihypertensives during surgery.

- A simple and practical way to optimize DBS surgery 


\section{INTRODUCTION}

2 Deep brain stimulation (DBS) has become a major technique for treating various neurological 3 and psychiatric disorders such as Parkinson's disease, essential tremor, dystonia, obsessive4 compulsive disorder or depression, to name but a few indications. ${ }^{26}$ Despite its widespread use, 5 surgical techniques differ widely and most centers rely on intraoperative microelectrode 6 recording and macrostimulation to refine electrode placement in the awake patient. During 7 awake surgery, patient comfort might be restricted due to prolonged operating time, pain and 8 withholding of prior medication, thereby triggering increased stress and elevated blood pressure 9 (BP). As high BP is a strong risk factors for intracranial hemorrhage (ICH) in DBS surgery, 10 reducing $\mathrm{BP}$ and pain is of utmost importance. ${ }^{40}$ In this retrospective analysis of prospectively 11 acquired data we investigate two different methods of local anesthesia for awake DBS and their 12 influence on BP, heart rate (HR) and the use of perioperative antihypertensive medication. 13 Furthermore, we compare the need for analgesics during surgery and the immediate 14 postoperative period in both groups. 


\section{METHODS}

2 Ethics approval

3 The study protocol was approved by the local ethics committee (KEK: ID 2017-00440, version

4 1.2). All patients gave their written consent to participation in the study.

\section{$5 \quad$ Patients}

6 Electronic data files of all adult patients who underwent stereotactic lead placement for DBS

7 between February 2015 and May 2017 were screened. Age younger than 18 years, patients that

8 received lead placement under general anesthesia (GA) or conscious sedation (defined as having

9 received either dexmedetomidine, propofol or benzodiazepines) were excluded. Intraoperative systolic BP (mean, peaks $\geq 160 \mathrm{mmHg}$ ) and mean HR values were defined as primary endpoints of the study. Intraoperative use of cardiovascular or analgesic medication, perioperative occurrence of ICH as seen in the postoperative control computed tomography (CT) scan, and doses of analgesics $24 \mathrm{~h}$ after frame fixation were defined as secondary endpoints. Patient characteristics such as sex, age, primary neurological disorder and known arterial hypertension were recorded. No patient was diagnosed with coagulopathy or under the influence of anticoagulant or anti-platelet drugs.

\section{Anesthetic procedure}

During the study period, a change of the in-house anesthesia protocol occurred. Before this time 19 point every patient underwent local infiltration anesthesia (LA) at pin insertion and incision sites. 20 After the change, every patient received a scalp block (SB). No further patient selection for the mode of anesthesia was performed. Between frame placement and end of surgery, continuous intra-arterial BP, HR and 3-channel electrocardiography monitoring were routinely performed.

23 Intravenous (i.v.) urapidil (Ebrantil®, Takeda, Opfikon, Switzerland) was administered to 24 prevent systolic BP pressure levels exceeding $160 \mathrm{mmHg}$. Remifentanil (Ultiva®, GSK, 25 Brentford, UK) was added i.v. whenever patients complained of periprocedural pain. Despite the 26 form anesthesia all further periprocedural interventions were equal. 
SB was performed by an experienced neuroanesthesiologist (FB) before frame fixation according to a defined standard operating procedure protocol. In brief, bilateral supraorbital, auriculotemporal and major and minor occipital nerve areas were targeted with a 23 gauge $(\mathrm{G})$ needle under sterile conditions and continuous monitoring of vital signs. Ropivacaine $0.75 \%$ with epinephrine 1:200.000 (5 $\mathrm{\mu g} / \mathrm{ml})\left(\right.$ Naropin ${ }^{\circledR}$, AstraZeneca, Cambridge, UK) was slowly injected into the subgaleal space with a dose of $1.5-2 \mathrm{ml}, 3-5 \mathrm{ml}, 5 \mathrm{ml}$ and $4 \mathrm{ml}$, respectively. ${ }^{14}$ Exclusively during instillation of ropivacaine and not during surgery, a mild sedation with dexmedetomidine (Dexdor®, Orion Pharma, Zug, Switzerland) was performed in few cases. No further application of local anesthesteics at the incision site was performed.

\section{Local infiltration anesthesia}

LA was performed by experienced functional neurosurgeons (LS, MO, PK) prior to frame placement. At the four pin insertion sites $3 \mathrm{ml}$ of lidocaine $1 \%$ (formula hospitalis, University of Zurich, Switzerland) and Bupivacaine 0.5\% (Carbostesin®, AstraZeneca, Cambridge, UK) (1:1) were administered via a $23 \mathrm{G}$ needle under sterile conditions. After transfer to the operation room $(\mathrm{OR})$, disinfection and sterile draping, the incision sites were similarly instilled with 3 - 5 $\mathrm{ml}$ at $3-4 \mathrm{~min}$ before incision.

\section{Surgical procedure}

All surgical interventions were performed by experienced functional neurosurgeons (LS, MO, PK). After instillation of either LA or SB, a Riechert-Mundinger stereotactic frame (Inomed, Emmendingen, Germany) was mounted on the patients' skull via four transcutaneous pin fixations (two frontal and occipital, respectively). Following stereotactic CT scan with contrast agent the patients were transferred to the OR. Direct targeting was performed using the FrameLink $^{\mathrm{TM}}$ planning system (Medtronic, Minneapolis, Minnesota, USA). DBS implantation was carried out by a frame-mounted drill (Precisis AG, Heidelberg, Germany) burr hole trepanation. Brain penetration was exclusively performed at systolic BP values under 160 $\mathrm{mmHg}$. An experienced neurologist conducted the intraoperative neurophysiological and clinical assessment. After final lead placement, an immediate postoperative native stereotactic CT was performed to verify the definite lead location and to exclude potential ICH. The implanted 
1 programmable generator (IPG) (Activa $\mathrm{PC}^{\mathrm{TM}}$, Medtronic, Minneapolis, Minnesota, USA) was

2 implanted under GA either subsequently or during a second surgery after three days.

3 Pin placement for stereotactic frame fixation was defined as the start of the surgery (time point $40)$.

\section{$6 \quad$ Statistics}

7 Statistical analysis was performed using the software SPSS Statistics ${ }^{\mathrm{TM}}$ (version 24, IBM Corp, 8 Armonk, New York, USA). Datasets were tested for normal distribution with the Kolmogorov9 Smirnov normality test. For normally distributed data, an unpaired 2-tailed student's $t$ test was 10 used to compare significance of means between two groups. In non-normally distributed data, an 11 unpaired Mann Whitney test was used to compare two samples. Data in text and graphs are 12 shown as mean \pm standard error of the mean (SEM). A $p$ value $\leq .05$ was considered significant 13 and indicated by “*”, $p$ values $\leq .01$ were indicated by “**”, and values $\leq .001$ by “***”. 


\section{RESULTS}

Between February 2015 and May 2017, 69 patients underwent DBS surgery at our department.

4 Of those, 47 patients matched the inclusion criteria and were further analyzed. 29 patients received LA at pin and incision sites, 18 received a SB. Patient demographic data are shown in Table 1. Mean surgery duration was $230.0 \pm 4.6 \mathrm{~min}(\mathrm{LA} 237.4 \pm 5.6 \mathrm{~min}$ vs SB $219.2 \pm 7.2$ 7 min).

LA patients showed significantly higher mean systolic BP during surgery than SB patients (LA $147.9 \pm 1.5 \mathrm{mmHg}$ vs SB $141.9 \pm 2.6 \mathrm{mmHg} ; 2$-tailed students t-test: $p=.04$; 95\%-CI: [-11.6; 0.4]; $\mathrm{r}=.31$ ) (Fig. 1). Systolic BP peaks $\geq 160 \mathrm{mmHg}$ were present more often in LA patients (LA $21.1 \pm 4.1 \%$ vs SB $11.9 \pm 3.6 \%$; Mann-Whitney-U test: $p=.11 ; \mathrm{r}=.23$ ) (Fig. 2) compared to the SB group but without reaching a statistical significant difference. The mean HR during surgery showed was significantly lower in the SB group compared to the LA group (LA $77.9 \pm$ 2.0 BPM vs SB 69.2 \pm 2.8 BPM; 2-tailed students t-test: $p=.01$; 95\%-CI: [-15.6; - 1.9]; $\mathrm{r}=.36$ )

During the postoperative course, doses of analgesics including paracetamol, metamizole and 28 (see supplementary material). To maintain a normotensive state, LA patients required significantly more antihypertensive medication compared to the SB group (LA $23.1 \pm 5.8 \mathrm{mg} / \mathrm{h}$ urapidil vs SB $3.8 \pm 1.2 \mathrm{mg} / \mathrm{h}$ urapidil; Mann-Whitney-U test: $p<.001 ; \mathrm{r}=.51$ ) (Fig. 3).

Regarding the time course of surgery, mean systolic BP was significantly higher during minutes 40-80 with similar mean values during the following course of surgery (Fig. 4). During this time period, relatively more patients were in hypertensive state with $\mathrm{BP} \geq 160 \mathrm{mmHg}$ (Fig. 5). The mean need for antihypertensives was significantly higher during most of surgery time points from minute 40 on (Fig. 6). For time course details see supplementary material.

Regarding analgesic medication, intraoperative doses of remifentanil, paracetamol (Perfalgan®, UPSA, Rueil Malmaison, France) and metamizole (Novaminsulfon, Sintetica, Mendrisio, Switzerland) showed no significant difference between the two groups (Table 2).

7 morphine (Sintetica, Mendrisio, Switzerland) showed no significant difference between LA and SB groups (Table 2). 
1 In 32 patients (LA $n=22, S B n=10$ ), implantation of the IPG was performed directly after lead

2 placement. In this subgroup, SB patients required significantly less remifentanil doses during the

3 second intervention (LA $0.583 \pm 0.049 \mathrm{mg} / \mathrm{h}$ remifentanil vs SB $0.223 \pm 0.044 \mathrm{mg} / \mathrm{h}$

4 remifentanil; Mann-Whitney-U test: $p=.003 ; \mathrm{r}=.53$ ) (Table 2). 


\section{DISCUSSION}

In this retrospective analysis of prospectively collected datasets, we compared LA and SB in patients undergoing awake DBS surgery according to $\mathrm{BP}, \mathrm{HR}$, intraoperative use of antihypertensive medication and perioperative need of analgesics.

SB for awake procedures in neurosurgery has been shown to be a safe method in both adults ${ }^{20}$ and children, ${ }^{24}$ although its analgesic effects are still controversially debated. ${ }^{35}$ During these special kinds of operations including frame-based stereotactic procedures, pain due to pin placement and skin incision needs to be sufficiently controlled.

In general, stereotactic DBS lead placement is considered a relatively safe technique with bleeding rates usually of only $2-4 \%$ (range, $0.0 \%-34.4 \%$ ). ${ }^{2,16}$ Because of its minimal invasive character, stereotactic procedures are prone for awake surgery in LA, to perform intraoperative neurophysiological target verification and clinical assessment. However, as the target regions are usually located deep in the brain, even a small ICH can be fatal. Different factors have been described to augment the risk of ICH in DBS patients. Microelectrode recordings, ${ }^{40}$ multiple brain trajectories ${ }^{3,8,17,31,40}$ and patient age ${ }^{9}$ as well as high $\mathrm{BP}^{4,33}$ seem to be major risk factors. Therefore, especially high BP must be meticulously avoided during surgery.

\section{Effect of scalp block on blood pressure and risk of hemorrhage}

In patients undergoing craniotomy under GA, it could be demonstrated that SB reduces the rate of arterial high BP or tachycardia in adults and children. ${ }^{10,14,19,33,38}$ In a study comparing LA and SB prior to pin placement for craniotomy under GA, SB was shown to significantly lower BP and HR when compared to saline or LA during and immediately after pin placement but not during the further course of surgery. ${ }^{6,12,18,23,28,32}$ Furthermore, it was shown that BP and HR were significantly more stable during stereotactic procedures with SB than under conscious sedation alone. $^{13}$

In our study, patients receiving SB showed a significantly lower mean BP, significantly lower HR and less hypertensive peaks during surgery as expected. Even though an averaged difference of $6 \mathrm{mmHg}$ over the whole surgery rmay seem small, this effect became more prominent during 
the first 90 min of surgery, which usually includes lead placement. Patients in the SB group required significantly less antihypertensive medication with an overall more stable BP profile over time. This phenomenon could also be found comparing SB and LA or saline for craniotomy under GA. ${ }^{21}$ In another study, patients without SB needed significantly deeper anesthesia to maintain normal BP and HR during craniotomy under GA. ${ }^{6}$ Both a single asymptomatic cortical ICH and a symptomatic ICH of the internal capsule occurred in the LA group in the present series. The patient with capsular ICH became symptomatic during surgery, whereas the cortical ICH was an incidental finding in the postoperative CT scan. The associated transient paresis of the right lower limb improved significantly within the first four months postoperatively. Interestingly, the patient suffering from capsular ICH had a known history of art. hypertension high systolic BP and a higher than average antihypertensives dose during surgery. However, as bleeding rates are typically low, direct conclusions on safety cannot be drawn from our cohort due to the relatively small sample size.

\section{Effect of scalp block on patient comfort}

Awake DBS can be a stressful experience for patients deprived from their disease specific medication or suffering from insufficient analgesia. Patient discomfort and pain are known to raise $\mathrm{BP}$ and $\mathrm{HR}^{34}$ Therefore, it might indirectly increase the risk of $\mathrm{ICH}$. On the other hand, BP and HR can be analyzed as surrogate parameters for patient discomfort during surgery. Pain control is usually established by applying i.v. sedative and pain medication (mainly propofol, fentanyl, remifentanil, or dexmedetomidine) with or without local anesthesia. Generally, local anesthesia can be either performed as LA at pin and incision sites or as SB. ${ }^{11,25,30,36}$ In a cohort undergoing radiosurgery, supplementing local anesthesia at the pin sites with SB reduced head pain better than LA alone. ${ }^{7,15}$ The procedure of SB itself was shown to be less painful than LA at pin sites, however no significant difference of pain during pin placement was present. ${ }^{27}$ Another study showed that a group receiving a combination of SB with psychological guidance required less propofol and remifentanil than a group treated with LA and sedation during DBS surgery. ${ }^{37}$ Pain rates during the early postoperative phase ${ }^{22}$ and the first $24 \mathrm{~h}^{1,5,6}$ after craniotomy under GA were reduced when SB was applied before surgery. The need for analgesics was reduced after infratentorial craniotomy ${ }^{29}$ but not for supratentorial craniotomy ${ }^{1}$ under GA. In our cohort, no 
differences in the use of analgesics during awake surgery were present. Along with the

2 hemodynamic parameters described above (effect of scalp block on BP and risk of ICH), this

3 may reflect an improved analgesic effect of the SB. During the postoperative period, no

4 differences in the use of the analgesics including opioids were seen. We suppose this could be

5 due to the minimal skin incisions during DBS.

6 In the subgroup of patients that underwent IPG implantation the same day of initial DBS surgery

$7 \quad(\mathrm{LA} n=23, \mathrm{SB} n=11)$, less opioids were necessary during GA in the SB group compared to the

8 LA group. We recognized a faster recovery in these patients. Still, this rests an unstructured

9 observation, opioid sparing procedures were shown to have beneficial effects on postoperative

10 vomiting and nausea in non-neurosurgical patients. ${ }^{39}$

11 There are several study limitations and caveats. Apart from its retrospective character, the small

12 sample size and number of DBS procedures decreases the statistical power of our study and

13 decisive conclusions cannot be reached. As PD in later stages in known to affect vegetative

14 functions, s.a. BP, the slightly higher proportion of PD patients in the LA group may contribute

15 to less stable hemodynamics in this cohort. Moreover the application of dexmedetomidine in few

16 cases may have interfered with hemodynamics, still, no signs of sedation were apparent during

17 surgery in these patients. Furthermore, a clear limitation is that no structured assessment of pain

18 was performed and the analgesics (paracetamol, metamizole) are usually prescribed on a fixed

19 basis during the immediate postoperative period. 
2 As most centers rely on microelectrode recording and clinical test stimulation during awake DBS

3 lead implantation, patient comfort as well as pain and BP control have high priority specially to

4 reduce the risk of $\mathrm{ICH}$. We could show that SB provides better hemodynamic control than LA

5 during lead placement at the pin insertion and incision sites. The hemodynamic stability is

6 reflected by the decreased use of urapidil during lead insertion. We therefore conclude that SB

7 might be superior to LA for patient comfort and risk reduction in awake DBS. However, larger

8 prospective randomized and controlled studies are necessary to further assess the impact of SB

9 on BP control and risk of ICH in DBS surgery.

10

11

12

13

14

15 
1. Akcil EF, Dilmen OK, Vehid H, Ibisoglu LS, Tunali Y: Which one is more effective for analgesia in infratentorial craniotomy? The scalp block or local anesthetic infiltration. Clin Neurol Neurosurg 154:98103, 2017

2. Akhigbe $\mathrm{T}$, Zolnourian A: Use of regional scalp block for pain management after craniotomy: Review of literature and critical appraisal of evidence. J Clin Neurosci 45:44-47, 2017

3. Alkhani A, Lozano AM: Pallidotomy for parkinson disease: a review of contemporary literature. $\mathbf{J}$ Neurosurg 94:43-49, 2001

4. Ben-Haim S, Asaad WF, Gale JT, Eskandar EN: Risk factors for hemorrhage during microelectrode-guided deep brain stimulation and the introduction of an improved microelectrode design. Neurosurgery 64:754-762; discussion 762-753, 2009

5. Bloomfield EL, Schubert A, Secic M, Barnett G, Shutway F, Ebrahim ZY: The influence of scalp infiltration with bupivacaine on hemodynamics and postoperative pain in adult patients undergoing craniotomy. Anesth Analg 87:579-582, 1998

6. Can BO, Bilgin $\mathrm{H}$ : Effects of scalp block with bupivacaine versus levobupivacaine on haemodynamic response to head pinning and comparative efficacies in postoperative analgesia: A randomized controlled trial. J Int Med Res 45:439-450, 2017

7. Chakrabarti R, Ghazanwy M, Tewari A: Anesthetic challenges for deep brain stimulation: a systematic approach. N Am J Med Sci 6:359-369, 2014

8. de Bie RM, de Haan RJ, Schuurman PR, Esselink RA, Bosch DA, Speelman JD: Morbidity and mortality following pallidotomy in Parkinson's disease: a systematic review. Neurology 58:1008-1012, 2002

9. Deep-Brain Stimulation for Parkinson's Disease Study G, Obeso JA, Olanow CW, RodriguezOroz MC, Krack P, Kumar R, et al: Deep-brain stimulation of the subthalamic nucleus or the pars interna of the globus pallidus in Parkinson's disease. N Engl J Med 345:956-963, 2001

10. Elias WJ, Sansur CA, Frysinger RC: Sulcal and ventricular trajectories in stereotactic surgery. J Neurosurg 110:201-207, 2009

11. Fagius J, Karhuvaara S, Sundlof G: The cold pressor test: effects on sympathetic nerve activity in human muscle and skin nerve fascicles. Acta Physiol Scand 137:325-334, 1989

12. Gazoni FM, Pouratian N, Nemergut EC: Effect of ropivacaine skull block on perioperative outcomes in patients with supratentorial brain tumors and comparison with remifentanil: a pilot study. $\mathbf{J}$ Neurosurg 109:44-49, 2008

13. Geze S, Yilmaz AA, Tuzuner F: The effect of scalp block and local infiltration on the haemodynamic and stress response to skull-pin placement for craniotomy. Eur J Anaesthesiol 26:298303, 2009

14. Gorgulho A, De Salles AA, Frighetto L, Behnke E: Incidence of hemorrhage associated with electrophysiological studies performed using macroelectrodes and microelectrodes in functional neurosurgery. J Neurosurg 102:888-896, 2005

15. Grant R, Gruenbaum SE, Gerrard J: Anaesthesia for deep brain stimulation: a review. Curr Opin Anaesthesiol 28:505-510, 2015

16. Guilfoyle MR, Helmy A, Duane D, Hutchinson PJ: Regional scalp block for postcraniotomy analgesia: a systematic review and meta-analysis. Anesth Analg 116:1093-1102, 2013

17. Hariz MI: Safety and risk of microelectrode recording in surgery for movement disorders. Stereotact Funct Neurosurg 78:146-157, 2002

18. Hartley EJ, Bissonnette B, St-Louis P, Rybczynski J, McLeod ME: Scalp infiltration with bupivacaine in pediatric brain surgery. Anesth Analg 73:29-32, 1991

19. Higuchi Y, lacono RP: Surgical complications in patients with Parkinson's disease after posteroventral pallidotomy. Neurosurgery 52:558-571; discussion 568-571, 2003

20. Kerscher C, Zimmermann M, Graf BM, Hansen E: [Scalp blocks. A useful technique for neurosurgery, dermatology, plastic surgery and pain therapy]. Anaesthesist 58:949-958; quiz 959-960, 2009

21. Kocuj F, Epple J, Polarz H, Tronnier VM, Martin E: Nerve blocks in stereotactic neurosurgery. Stereotact Funct Neurosurg 78:29-38, 2002 
22. Lange M, Zech N, Seemann M, Janzen A, Halbing D, Zeman F, et al: Anesthesiologic regimen and intraoperative delirium in deep brain stimulation surgery for Parkinson's disease. $J$ Neurol Sci 355:168-173, 2015

23. Lee EJ, Lee MY, Shyr MH, Cheng JT, Toung TJ, Mirski MA, et al: Adjuvant bupivacaine scalp block facilitates stabilization of hemodynamics in patients undergoing craniotomy with general anesthesia: a preliminary report. J Clin Anesth 18:490-494, 2006

24. Lobo FA, Wagemakers M, Absalom AR: Anaesthesia for awake craniotomy. $\mathbf{B r} \mathbf{J}$ Anaesth 116:740-744, 2016

25. Maixner W, Gracely RH, Zuniga JR, Humphrey CB, Bloodworth GR: Cardiovascular and sensory responses to forearm ischemia and dynamic hand exercise. Am J Physiol 259:R1156-1163, 1990

26. Marks WJ, Cambridge University P: Deep brain stimulation management. Cambridge: Cambridge University Press, 2015

27. McCormick PJ, Osborn IP, Germano IM, Green S, Deiner SG: Scalp nerve blockade reduces pain after headframe placement in radiosurgery: a double blind, randomized clinical trial. Middle East $\mathbf{J}$ Anaesthesiol 22:79-85, 2013

28. Mohammadi SS, Shahbazian E, Shoeibi G, Almassi F: Effect of scalp infiltration with Bupivacaine on early hemodynamic responses during craniotomy under general anesthesia. Pak J Biol Sci 12:603606, 2009

29. Nguyen A, Girard F, Boudreault D, Fugere F, Ruel M, Moumdjian R, et al: Scalp nerve blocks decrease the severity of pain after craniotomy. Anesth Analg 93:1272-1276, 2001

30. Nordin M, Fagius J: Effect of noxious stimulation on sympathetic vasoconstrictor outflow to human muscles. J Physiol 489 ( Pt 3):885-894, 1995

31. Palur RS, Berk C, Schulzer M, Honey CR: A metaanalysis comparing the results of pallidotomy performed using microelectrode recording or macroelectrode stimulation. J Neurosurg 96:1058-1062, 2002

32. Pinosky ML, Fishman RL, Reeves ST, Harvey SC, Patel S, Palesch Y, et al: The effect of bupivacaine skull block on the hemodynamic response to craniotomy. Anesth Analg 83:1256-1261, 1996 33. Sansur CA, Frysinger RC, Pouratian N, Fu KM, Bittl M, Oskouian RJ, et al: Incidence of symptomatic hemorrhage after stereotactic electrode placement. J Neurosurg 107:998-1003, 2007

34. Shiau JM, Chen TY, Tseng CC, Chang PJ, Tsai YC, Chang CL, et al: Combination of bupivacaine scalp circuit infiltration with general anesthesia to control the hemodynamic response in craniotomy patients. Acta Anaesthesiol Sin 36:215-220, 1998

35. Stokes MA, Soriano SG, Tarbell NJ, Loeffler JS, Alexander E, 3rd, Black PM, et al: Anesthesia for stereotactic radiosurgery in children. J Neurosurg Anesthesiol 7:100-108, 1995

36. Terkelsen AJ, Molgaard H, Hansen J, Andersen OK, Jensen TS: Acute pain increases heart rate: differential mechanisms during rest and mental stress. Auton Neurosci 121:101-109, 2005

37. Watson R, Leslie K: Nerve blocks versus subcutaneous infiltration for stereotactic frame placement. Anesth Analg 92:424-427, 2001

38. Xiaowu $\mathrm{H}$, Xiufeng $\mathrm{J}$, Xiaoping $\mathrm{Z}$, Bin $\mathrm{H}$, Laixing $\mathrm{W}$, Yiqun $\mathrm{C}$, et al: Risks of intracranial hemorrhage in patients with Parkinson's disease receiving deep brain stimulation and ablation. Parkinsonism Relat Disord 16:96-100, 2010

39. Ziemann-Gimmel P, Goldfarb AA, Koppman J, Marema RT: Opioid-free total intravenous anaesthesia reduces postoperative nausea and vomiting in bariatric surgery beyond triple prophylaxis. $\mathrm{Br}$ J Anaesth 112:906-911, 2014

40. Zrinzo L, Foltynie T, Limousin P, Hariz Ml: Reducing hemorrhagic complications in functional neurosurgery: a large case series and systematic literature review. J Neurosurg 116:84-94, 2012 
Table 1: demographic data

\begin{tabular}{|c|c|c|}
\hline & LA & SB \\
\hline $\mathrm{N}$ & 29 & 18 \\
\hline $\operatorname{Sex}(m: f)$ & $15: 14$ & $9: 9$ \\
\hline Age $(y \pm S D)$ & $63.8 \pm 9.6$ & $65.2 \pm 10.5$ \\
\hline Disease (PD : ET) & $26: 3$ & $13: 5$ \\
\hline $\begin{array}{l}\text { History of hypertension } \\
\text { (n) }\end{array}$ & 6 & 5 \\
\hline \multicolumn{3}{|c|}{$\begin{array}{l}\mathrm{LA}=\text { local anesthesia, } \mathrm{SB}=\text { scalp block, } \mathrm{N}=\text { number, } \mathrm{m}= \\
\text { male, } \mathrm{f}=\text { female, } \mathrm{SD}=\text { standard deviation, } \mathrm{PD}= \\
\text { Parkinson`s disease, } \mathrm{ET}=\text { essential tremor }\end{array}$} \\
\hline
\end{tabular}


Table 2: perioperative drug administration

\begin{tabular}{|c|c|c|c|c|}
\hline Time Point & Drug & LA & SB & p-value \\
\hline \multicolumn{5}{|l|}{$\begin{array}{l}\text { First } \\
\text { intervention }\end{array}$} \\
\hline intra-op & Paracetamol $(\mathrm{g} / \mathrm{h} \pm \mathrm{SEM})$ & $0.02 \pm 0.02$ & $0.11 \pm 0.03$ & .87 \\
\hline \multirow{5}{*}{$\begin{array}{l}24 \mathrm{~h} \text { post- } \\
\text { op }\end{array}$} & Metamizole $(\mathrm{g} / \mathrm{h} \pm \mathrm{SEM})$ & $0.01 \pm 0.02$ & $0.06 \pm 0.03$ & .53 \\
\hline & Remifentanil $(\mathrm{mg} / \mathrm{h} \pm \mathrm{SEM})$ & $0.000 \pm 0.000$ & $0.040 \pm 0.024$ & .11 \\
\hline & Paracetamol $(\mathrm{g} / 24 \mathrm{~h} \pm \mathrm{SEM})$ & $2.48 \pm 0.16$ & $1.89 \pm 0.28$ & .09 \\
\hline & Metamizole $(\mathrm{g} / 24 \mathrm{~h} \pm \mathrm{SEM})$ & $1.88 \pm 0.25$ & $1.22 \pm 0.27$ & .08 \\
\hline & Morphine $(\mathrm{mg} / 24 \mathrm{~h} \pm \mathrm{SEM})$ & $0.69 \pm 0.48$ & $0.22 \pm 0.22$ & .82 \\
\hline $\begin{array}{l}\text { Second } \\
\text { intervention }\end{array}$ & Remifentanil $(\mathrm{mg} / \mathrm{h} \pm \mathrm{SEM})$ & $0.583 \pm 0.049$ & $0.223 \pm 0.044$ & $.003 * *$ \\
\hline
\end{tabular}


Table supp.

\begin{tabular}{|c|c|c|c|c|c|c|c|c|c|c|}
\hline \multirow{3}{*}{$\begin{array}{c}\begin{array}{c}\text { Surgery } \\
\text { time } \\
(\mathrm{min})\end{array} \\
0\end{array}$} & \multicolumn{3}{|c|}{$\begin{array}{c}\text { SBP } \\
(\mathrm{mmHg} ; \text { mean } \pm \text { SEM })\end{array}$} & \multirow{2}{*}{\multicolumn{2}{|c|}{$\begin{array}{c}\text { Hypertension } \\
(\%)\end{array}$}} & \multicolumn{3}{|c|}{$\begin{array}{l}\text { Antihypertensives } \\
(\mathrm{mg} / \mathrm{h} ; \text { mean } \pm \mathrm{SEM})\end{array}$} & \multirow{2}{*}{\multicolumn{2}{|c|}{$\begin{array}{c}\text { Group size } \\
\text { (n) }\end{array}$}} \\
\hline & \multicolumn{2}{|c|}{ LA vs SB } & \multirow{2}{*}{$\frac{\mathrm{p}}{\mathrm{ns}}$} & & & \multicolumn{2}{|c|}{ LA vs SB } & \multirow{2}{*}{$\frac{\mathrm{p}}{\mathrm{ns}}$} & & \\
\hline & $\begin{array}{l}147.0 \\
\pm 4.3\end{array}$ & $\begin{array}{l}136.2 \\
\pm 4.6\end{array}$ & & 0.0 & 5.6 & 0.0 & 0.0 & & 4 & 18 \\
\hline 10 & $\begin{array}{l}151.2 \\
\pm 8.2\end{array}$ & $\begin{array}{l}135.7 \\
\pm 3.6\end{array}$ & ns & 60.0 & 5.6 & 0.0 & 0.0 & ns & 5 & 18 \\
\hline 20 & $\begin{array}{l}152.9 \\
\pm 6.8\end{array}$ & $\begin{array}{l}140.9 \\
\pm 4.2\end{array}$ & ns & 55.6 & 22.2 & 0.0 & 0.0 & ns & 9 & 18 \\
\hline 30 & $\begin{array}{l}153.1 \\
\pm 5.1\end{array}$ & $\begin{array}{l}143.2 \\
\pm 3.7\end{array}$ & ns & 43.8 & 16.7 & $\begin{array}{c}3.1 \\
\pm 2.3\end{array}$ & 0.0 & ns & 16 & 18 \\
\hline 40 & $\begin{array}{l}162.4 \\
\pm 4.2\end{array}$ & $\begin{array}{l}141.6 \\
\pm 3.8\end{array}$ & .001 & 56.5 & 22.2 & $\begin{array}{r}13.1 \\
\pm 5.5\end{array}$ & 0.0 & .041 & 23 & 18 \\
\hline 50 & $\begin{array}{r}158.7 \\
\pm 2.9\end{array}$ & $\begin{array}{l}143.7 \\
\pm 4.6\end{array}$ & .006 & 46.2 & 16.7 & $\begin{array}{r}18.3 \\
\pm 7.5\end{array}$ & $\begin{array}{c}5.0 \\
\pm 5.0\end{array}$ & ns & 26 & 18 \\
\hline 60 & $\begin{array}{l}161.7 \\
\pm 3.6\end{array}$ & $\begin{array}{l}139.1 \\
\pm 4.3\end{array}$ & .0001 & 57.1 & 5.6 & $\begin{array}{r}23.3 \\
\pm 6.0\end{array}$ & $\begin{array}{c}3.3 \\
\pm 2.3\end{array}$ & .007 & 28 & 18 \\
\hline 70 & $\begin{array}{l}151.9 \\
\pm 4.3\end{array}$ & $\begin{array}{l}137.9 \\
\pm 3.3\end{array}$ & .024 & 42.9 & 5.6 & $\begin{array}{r}22.1 \\
\pm 5.8\end{array}$ & $\begin{array}{r}6.7 \\
\pm 3.9\end{array}$ & .014 & 28 & 18 \\
\hline 80 & $\begin{array}{l}149.9 \\
\pm 2.9\end{array}$ & $\begin{array}{l}140.1 \\
\pm 3.9\end{array}$ & .037 & 24.1 & 16.7 & $\begin{array}{r}18.7 \\
\pm 5.3\end{array}$ & $\begin{array}{r}1.7 \\
\pm 1.7\end{array}$ & .002 & 29 & 18 \\
\hline 90 & $\begin{array}{l}150.6 \\
\pm 2.8\end{array}$ & $\begin{array}{l}143.7 \\
\pm 4.1\end{array}$ & ns & 34.5 & 27.8 & $\begin{array}{r}26.7 \\
\pm 8.0\end{array}$ & $\begin{array}{r}11.7 \\
\pm 7.3\end{array}$ & ns & 29 & 18 \\
\hline 100 & $\begin{array}{l}148.6 \\
\pm 2.7\end{array}$ & $\begin{array}{l}141.2 \\
\pm 3.2\end{array}$ & ns & 24.1 & 5.6 & $\begin{array}{r}22.8 \\
\pm 5.8\end{array}$ & $\begin{array}{r}11.7 \\
\pm 6.0\end{array}$ & ns & 29 & 18 \\
\hline 110 & $\begin{array}{l}144.9 \\
\pm 1.9\end{array}$ & $\begin{array}{l}144.6 \\
\pm 3.6\end{array}$ & ns & 10.3 & 11.1 & $\begin{array}{l}20.4 \\
\pm 6.1\end{array}$ & $\begin{array}{c}6.7 \\
\pm 5.2\end{array}$ & .007 & 29 & 18 \\
\hline 120 & $\begin{array}{l}144.9 \\
\pm 2.0\end{array}$ & $\begin{array}{l}143.4 \\
\pm 3.1\end{array}$ & ns & 6.9 & 22.2 & $\begin{array}{r}24.7 \\
\pm 5.2\end{array}$ & $\begin{array}{r}1.7 \\
\pm 1.7\end{array}$ & .0001 & 29 & 18 \\
\hline 130 & $\begin{array}{l}145.3 \\
\pm 2.2\end{array}$ & $\begin{array}{l}145.1 \\
\pm 3.6\end{array}$ & ns & 13.8 & 11.1 & $\begin{array}{r}23.0 \\
\pm 6.5\end{array}$ & $\begin{array}{r}10.0 \\
\pm 4.9\end{array}$ & .046 & 29 & 18 \\
\hline 140 & $\begin{array}{l}145.2 \\
\pm 1.7\end{array}$ & $\begin{array}{c}142.4 \\
\pm 2.9\end{array}$ & ns & 10.3 & 5.6 & $\begin{array}{r}15.1 \\
\pm 4.3\end{array}$ & $\begin{array}{c}3.3 \\
\pm 2.3\end{array}$ & .009 & 29 & 18 \\
\hline 150 & $\begin{array}{l}145.9 \\
\pm 1.9\end{array}$ & $\begin{array}{l}141.3 \\
\pm 3.0\end{array}$ & ns & 10.3 & 5.6 & $\begin{array}{c}26.3 \\
\pm 10.3\end{array}$ & $\begin{array}{c}3.3 \\
\pm 2.3\end{array}$ & .007 & 29 & 18 \\
\hline 160 & $\begin{array}{l}142.9 \\
\pm 1.8\end{array}$ & $\begin{array}{l}142.3 \\
\pm 3.3\end{array}$ & ns & 3.5 & 5.6 & $\begin{array}{c}40.9 \\
\pm 16.4\end{array}$ & $\begin{array}{r}3.3 \\
\pm 3.3\end{array}$ & .001 & 29 & 18 \\
\hline 170 & $\begin{array}{l}144.9 \\
\pm 2.6\end{array}$ & $\begin{array}{l}143.6 \\
\pm 3.4\end{array}$ & ns & 13.8 & 16.7 & $\begin{array}{c}48.8 \\
\pm 39.2\end{array}$ & $\begin{array}{c}8.3 \\
\pm 5.8\end{array}$ & .028 & 29 & 18 \\
\hline 180 & $\begin{array}{c}144.8 \\
\pm 2.4\end{array}$ & $\begin{array}{l}142.6 \\
\pm 2.9\end{array}$ & ns & 10.7 & 17.7 & $\begin{array}{r}45.2 \\
\pm 23.8\end{array}$ & $\begin{array}{c}5.0 \\
\pm 3.6\end{array}$ & .005 & 28 & 17 \\
\hline 190 & $\begin{array}{c}146.1 \\
\pm 2.3\end{array}$ & $\begin{array}{l}144.5 \\
\pm 3.3\end{array}$ & ns & 22.2 & 17.7 & $\begin{array}{r}12.9 \\
\pm 4.1\end{array}$ & $\begin{array}{c}6.7 \\
\pm 3.9\end{array}$ & ns & 27 & 17 \\
\hline 200 & $\begin{array}{l}144.7 \\
\pm 2.2\end{array}$ & $\begin{array}{l}140.0 \\
\pm 3.5\end{array}$ & ns & 14.8 & 7.7 & $\begin{array}{r}22.3 \\
\pm 7.1\end{array}$ & 0.0 & .0001 & 27 & 13 \\
\hline 210 & $\begin{array}{c}146.2 \\
\pm 2.1\end{array}$ & $\begin{array}{l}142.9 \\
\pm 3.7\end{array}$ & ns & 8.0 & 8.3 & $\begin{array}{r}24.4 \\
\pm 8.7\end{array}$ & 0.0 & .002 & 25 & 12 \\
\hline 220 & $\begin{array}{l}145.6 \\
\pm 2.5\end{array}$ & $\begin{array}{c}143.8 \\
\pm 3.6\end{array}$ & ns & 8.7 & 0.0 & $\begin{array}{r}24.8 \\
\pm 8.7\end{array}$ & 0.0 & .012 & 23 & 10 \\
\hline 230 & $\begin{array}{c}142.4 \\
\pm 3.1\end{array}$ & $\begin{array}{c}145.9 \\
\pm 3.1\end{array}$ & ns & 17.4 & 0.0 & $\begin{array}{r}16.1 \\
\pm 6.4\end{array}$ & 0.0 & .038 & 23 & 7 \\
\hline 240 & $\begin{array}{c}141.3 \\
\pm 3.8\end{array}$ & $\begin{array}{r}142.0 \\
\pm 11.1\end{array}$ & ns & 6.3 & 0.0 & $\begin{array}{r}18.7 \\
\pm 7.8\end{array}$ & 0.0 & ns & 16 & 3 \\
\hline 250 & $\begin{array}{l}131.9 \\
\pm 3.5\end{array}$ & $\begin{array}{r}134.7 \\
\pm 17.6\end{array}$ & ns & 0.0 & 0.0 & $\begin{array}{c}4.9 \\
\pm 3.0\end{array}$ & 0.0 & ns & 11 & 3 \\
\hline 260 & $\begin{array}{l}140.5 \\
\pm 2.5\end{array}$ & $\begin{array}{l}144.0 \\
\pm 7.8\end{array}$ & ns & 0.0 & 0.0 & $\begin{array}{c}5.3 \\
\pm 3.7\end{array}$ & 0.0 & ns & 8 & 3 \\
\hline 270 & 138.7 & 147.3 & ns & 0.0 & 0.0 & 5.1 & 0.0 & ns & 6 & 3 \\
\hline
\end{tabular}




\begin{tabular}{|c|cc|c|cc|cc|c|cc|} 
& \pm 4.2 & \pm 8.7 & & & & \pm 4.2 & & \\
280 & 139.3 & 130.0 & ns & 0.0 & 0.0 & 0.0 & 0.0 & ns & 4 & 1 \\
290 & 125.0 & - & - & 0.0 & - & 0.0 & - & - & 1 & 0 \\
\hline
\end{tabular}

$\mathrm{SBP}=$ systolic blood pressure, $\mathrm{LA}=$ local anesthesia, $\mathrm{SB}=$ scalp block, $\mathrm{SEM}=$ standard error mean, $\mathrm{n}=$ number, $\mathrm{ns}=$ non significant 


\section{Systolic blood pressure \\ -

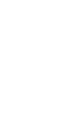

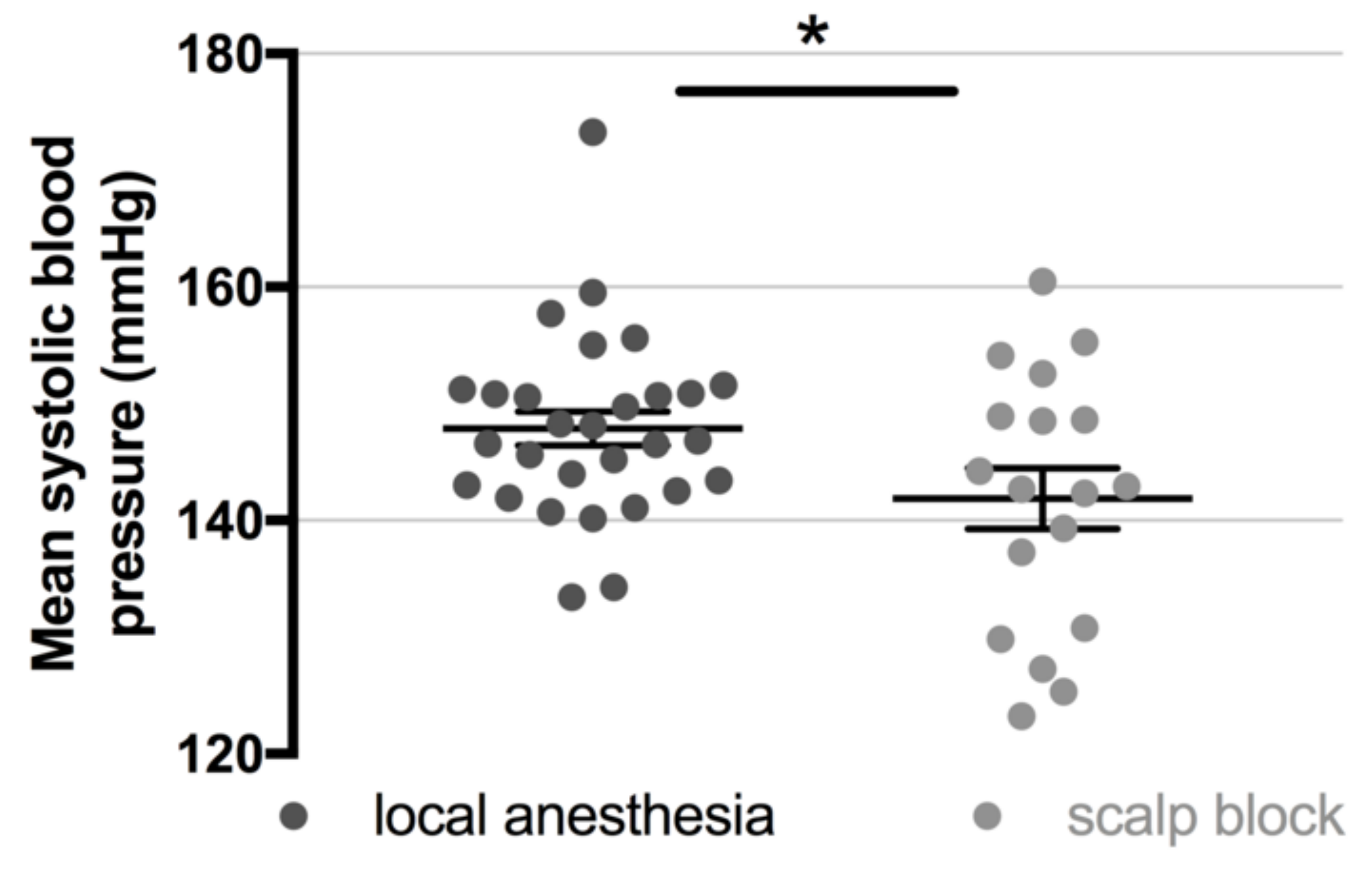

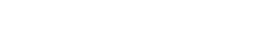




\section{Hypertensive state}

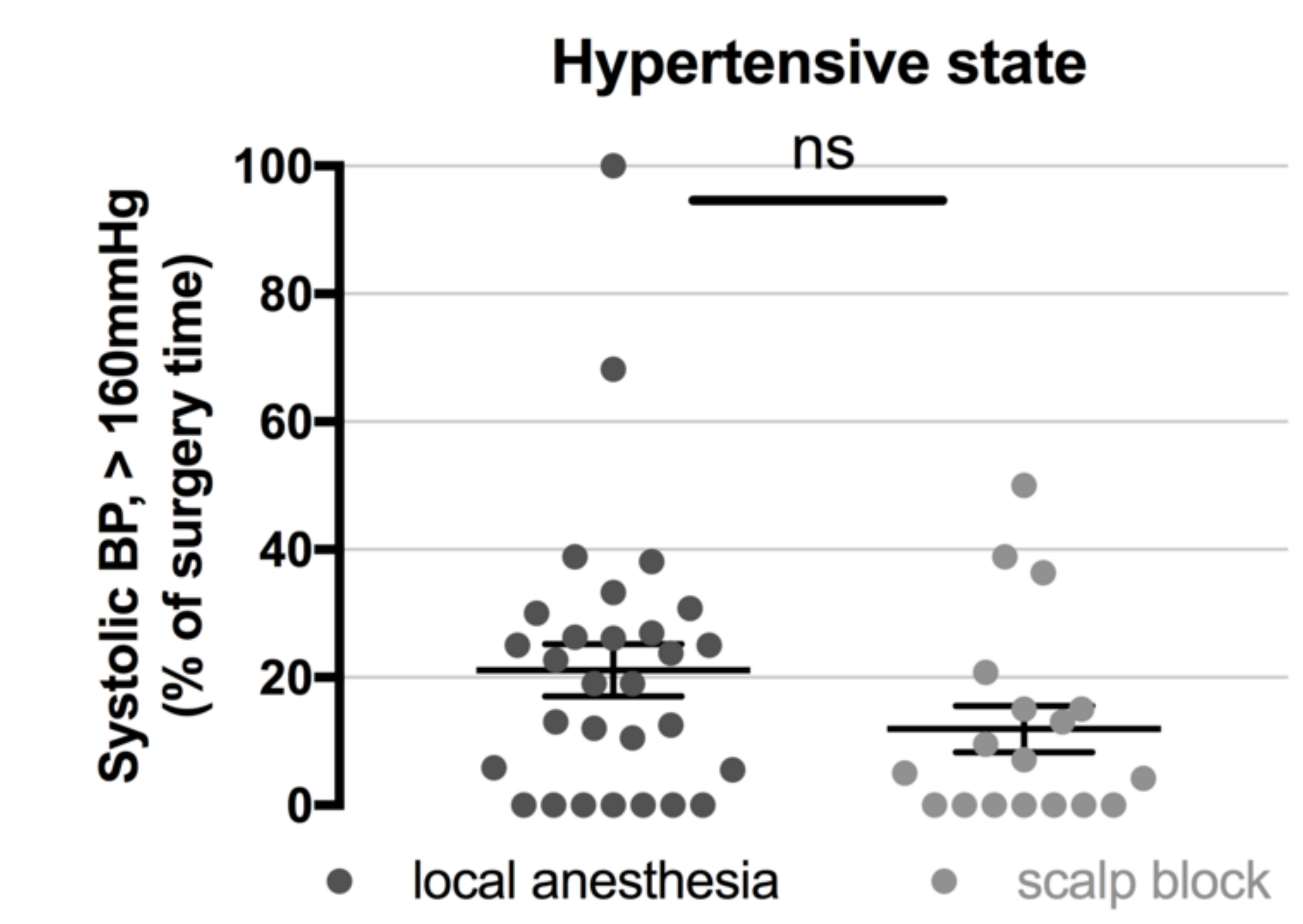

.

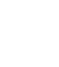

.

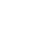

$\frac{000}{\text { anesthesia }}$
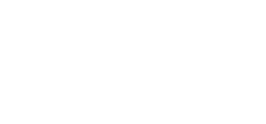

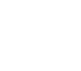




\section{Antihypertensives}

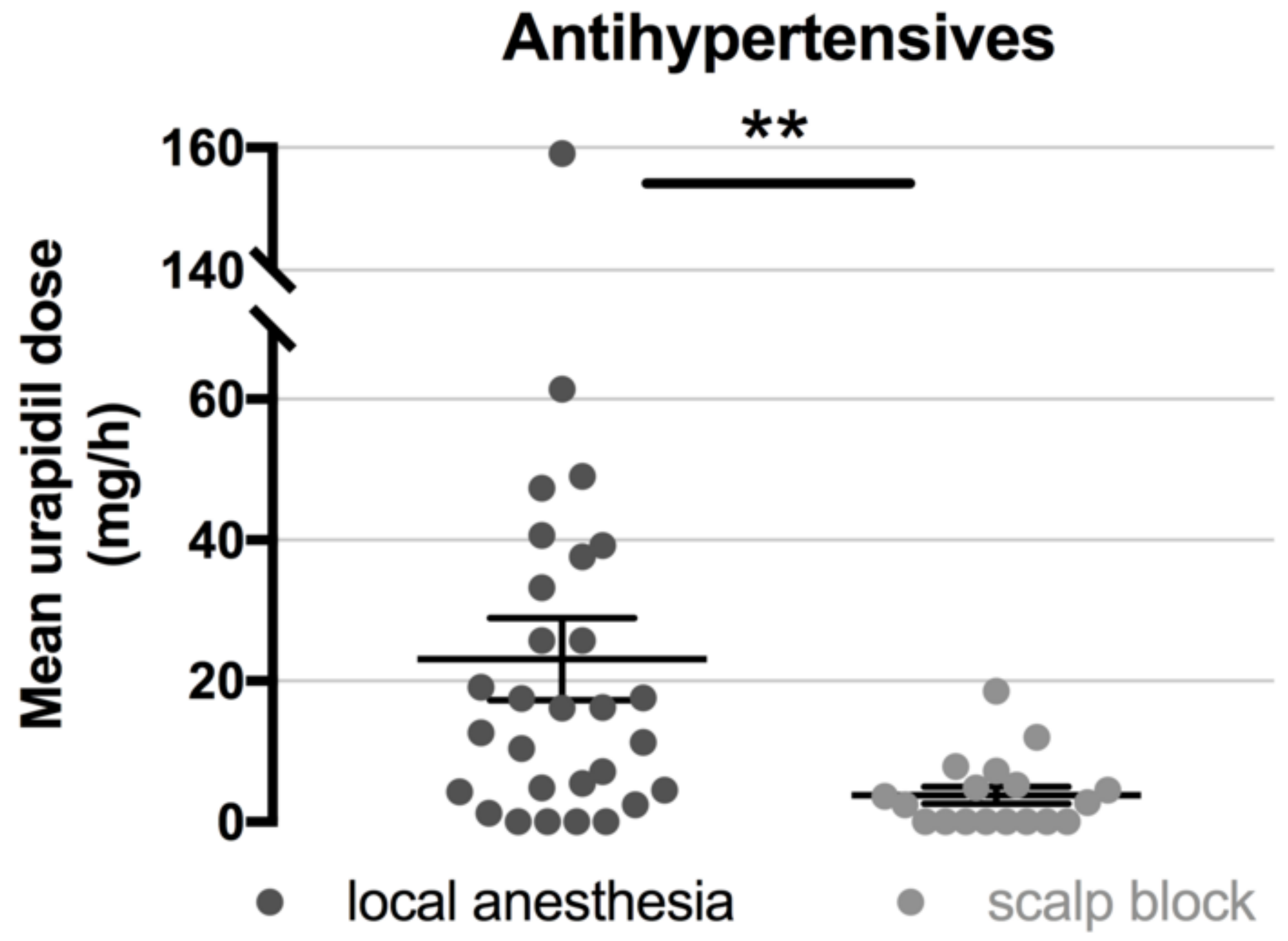




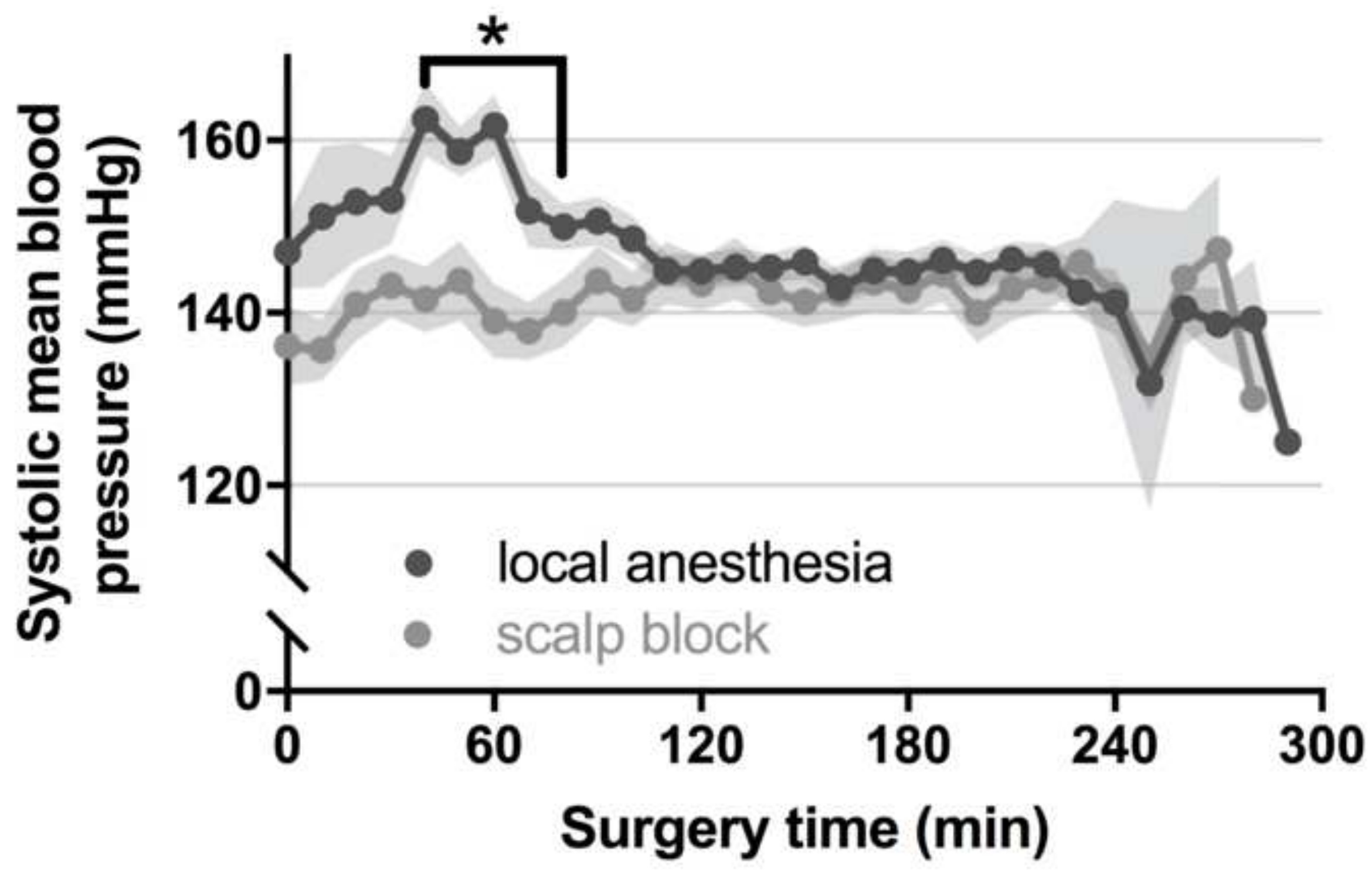




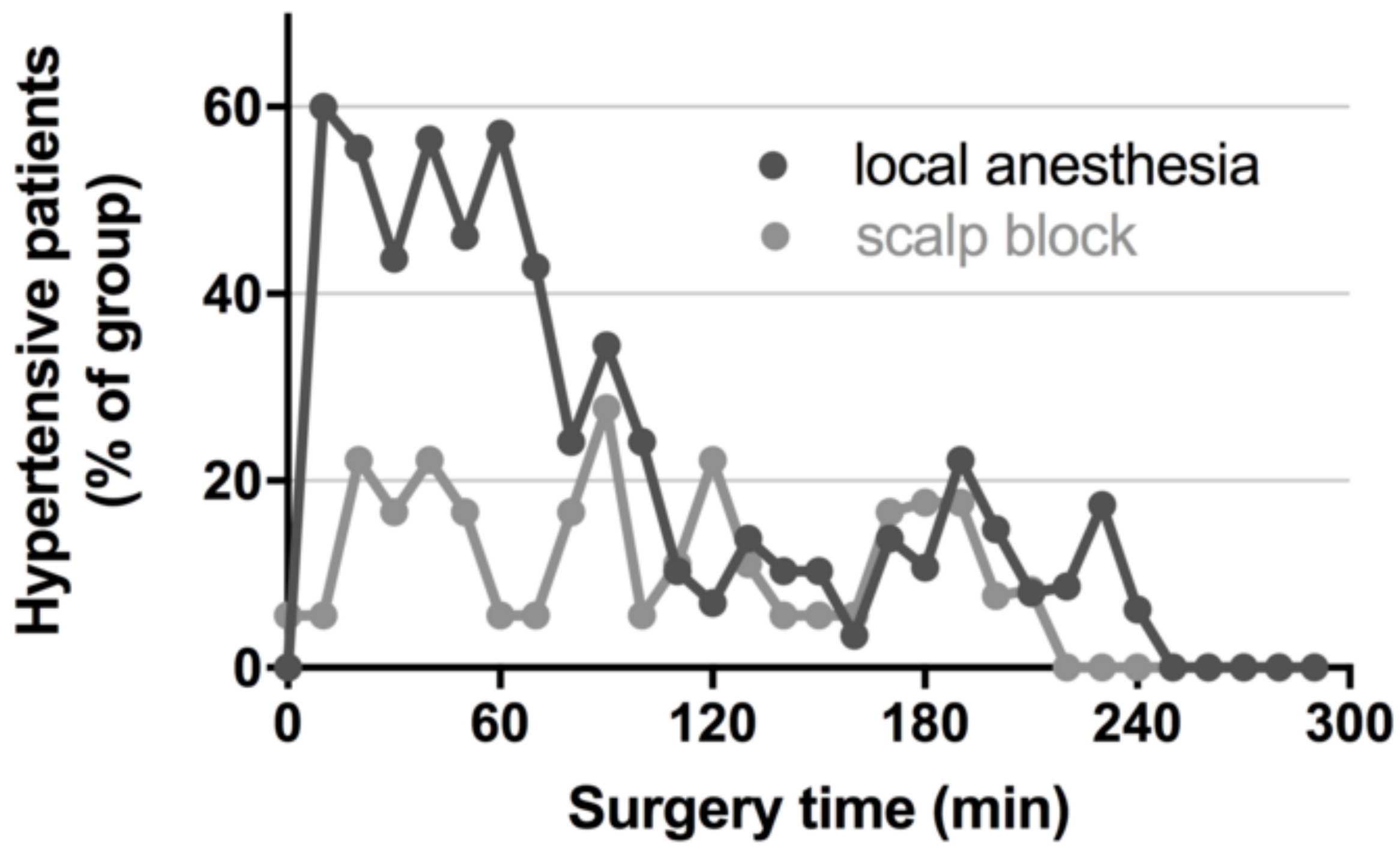




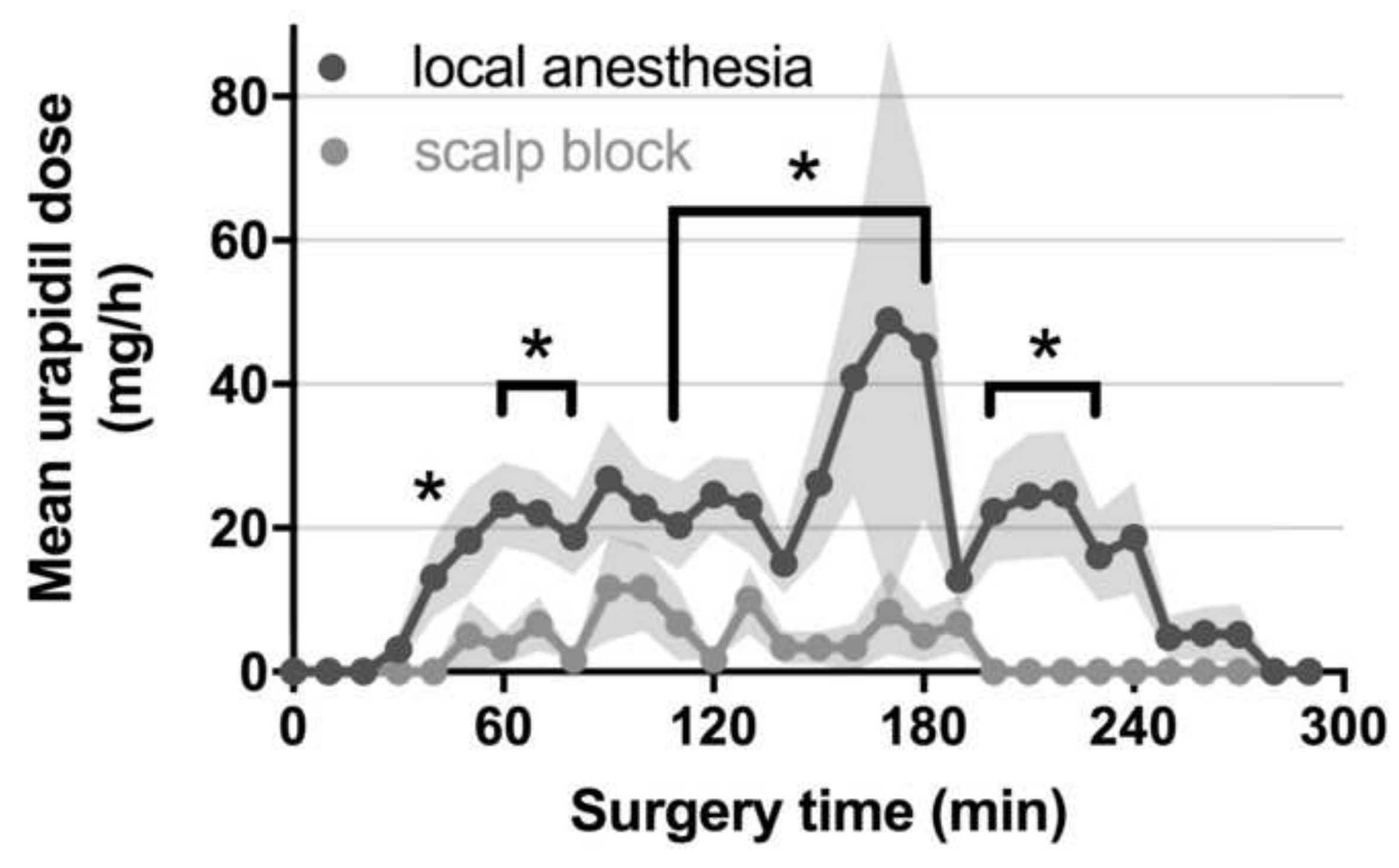




\section{Heart rate}

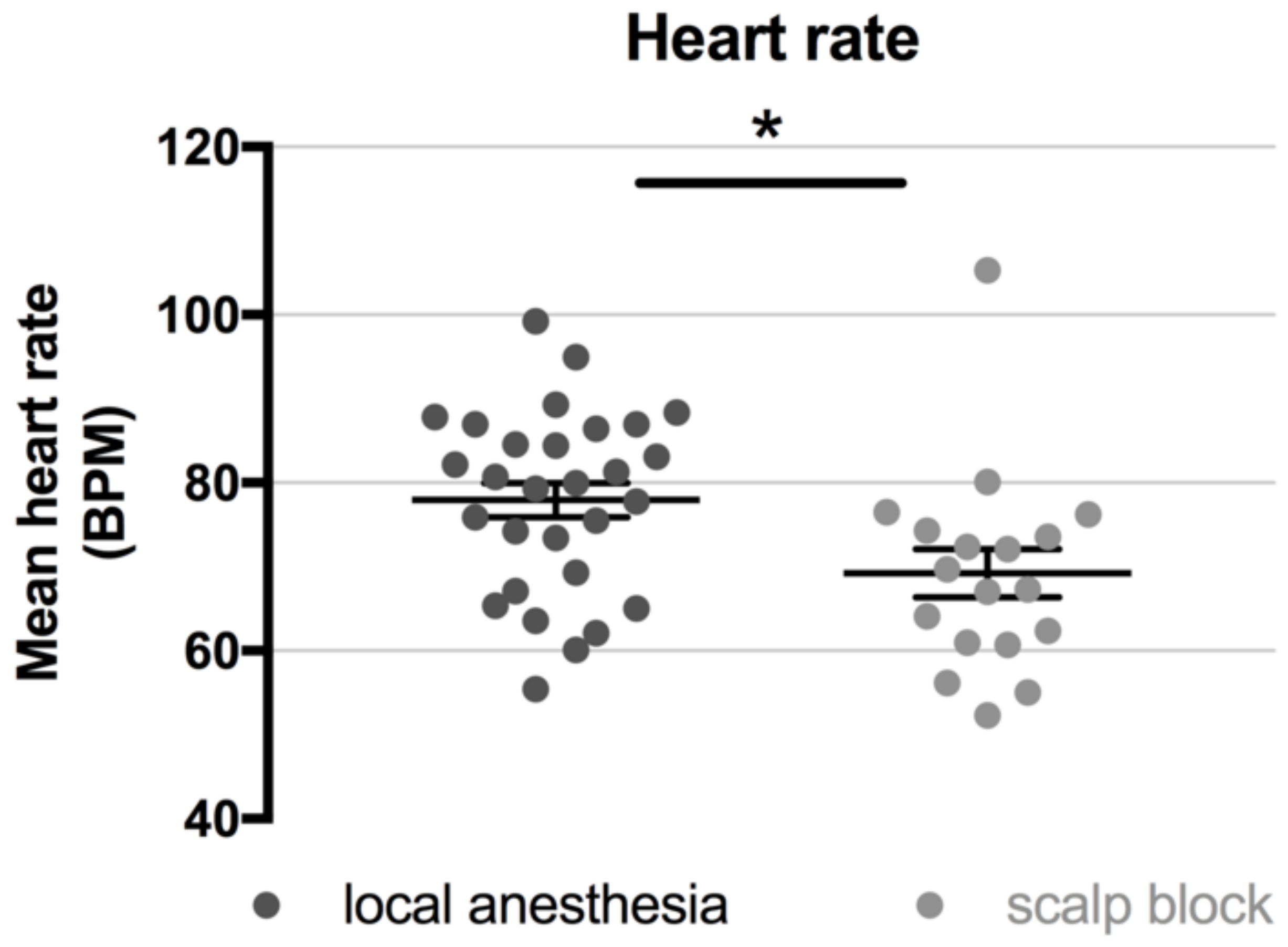

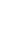

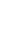

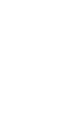

